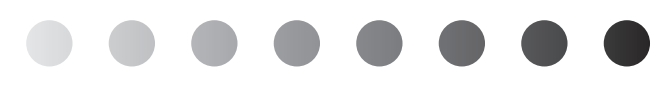

\title{
AFECTIVIDAD Y ESPACIO BIOGRÁFICO EN CENTROAMÉRICA. DOS CARTAS DE GUERRA Y EXILIO
}

\begin{abstract}
Ana Lorena Carrillo Padilla*
Resumen: Este artículo es parte de una investigación en curso, de mayor amplitud y alcance. Aquí se discute la pertinencia teórica del estudio de los afectos o la afectividad en un marco cultural para el análisis de textos autobiográficos producidos durante el conflicto armado en Centroamérica en los años ochenta del siglo XX. En la primera parte se hace una presentación general del tema de los afectos y el espacio biográfico. En la segunda parte se presenta un somero estado de la cuestión en Centroamérica, con énfasis en Guatemala. En la tercera parte y final se analizan dos piezas de un pequeño epistolario familiar, como parte de un -todavía inexplorado- espacio biográfico centroamericano del conflicto armado, a modo de ejemplo de abordaje realizado desde diversas perspectivas, entre ellas la afectividad.

Palabras clave: afectividad; correspondencia; Centroamérica; Guatemala; guerra; exilio; historia.

Abstract: This article is part of a larger and broader research project in course. What is discussed here is the theoretical relevance of the affect studies or affectivity studies in a cultural framework for the analysis of autobiographical texts produced during the armed conflict in Central America during the 80 's decade of the XX century. In the first part of this text a general presentation Fecha de recepción: 01/06/2017-Fecha de aceptación: 01/07/2017

* Guatemalteca-mexicana. Doctora en Estudios Latinoamericanos (2004), Universidad Nacional Autónoma de México (UNAM). Profesora e investigadora en el Instituto de Ciencias Sociales y Humanidades “Alfonso Vélez Pliego", Benemérita Universidad Autónoma de Puebla (BUAP). Correo electrónico: lorencarr@yahoo.com
\end{abstract}


of the themes of affect and biographical space is outlined. On the second part, a brief state of the art is presented as it relates to Central America with an emphasis on Guatemala. On the third and last part, two pieces of a small collection of family letters are analyzed. This is done within -a yet to be explored-Central American Biographical Space of the Armed Conflict as a mode or example as to how to approach and read/analyze this literature from diverse perspectives, one of them being that of affectivity.

Keywords: Affectivity; Correspondence; Central America; Guatemala; War; Exile; History.

\section{Afectividad y espacio biográfico. Referencias metodológicas}

Aunque los orígenes y enfoques del estudio de los afectos son muchos y diversos, en la segunda mitad del siglo XX se multiplicaron y de ellos proviene su desarrollo actual. ${ }^{1}$ El renovado interés en la afectividad -o bien en los sentimientos o las emociones- en América Latina se relaciona, al parecer, con el hecho de que la o las generaciones que vivieron siendo jóvenes o niños en los sesenta, setenta y ochenta encaran, sin adaptarse plenamente, dos situaciones históricas: una novedad del capitalismo en su etapa actual centrada en la subordinación totalizadora del tiempo, el espacio y la vida social a la lógica del mercado ${ }^{2}$ por un lado, y el desgaste de las interpretaciones del pasado reciente en que se han reciclado una y otra vez los tópicos de la épica revolucionaria, de los sujetos y de la derrota en términos de lo políticamente aceptable o correcto, por otro. En Centroamérica, los conflictos armados de las décadas de los setenta y ochenta del siglo pasado han sido analizados en una copiosa bibliografía que no podemos citar aquí, sin embargo, poco se ha estudiado en términos culturales y de la afectividad. El interés en los afectos, las pasiones y los sentimientos - sin entrar aquí a la discusión sobre sus diferencias, que es un problema de implicaciones epistémicas- podría ser el síntoma de una resistencia política/afectiva a que el propio pasado sea devorado por la indiferencia o la "petrificación" histórica que imponen tanto aquella lógica como aquel desgaste. Con la intuición de que el amor, el llanto, el miedo, el odio y la

1 Para una síntesis del recorrido del "giro afectivo" en sus antecedentes en las Ciencias Sociales, véase el artículo de Giazú Enciso Domínguez y Alí Lara, "Emociones y ciencias sociales en el siglo XX: La precuela del Giro Afectivo", Athenea Digital. Revista de Pensamiento e Investigación Social (España) 14, n. 1 (marzo 2014): 263-288, DOI: https://doi.org/10.5565/ $\mathrm{rev} / \mathrm{athenead} / \mathrm{v} 14 \mathrm{n} 1.1094$.

2 Abril Trigo, "La función de los afectos en la economía político-libidinal”, en: El lenguaje de la emociones. Afecto y cultura en América Latina, (eds.) Mabel Moraña e Ignacio Sánchez Prado (Madrid-Frankfurt: Iberoamericana; Vervuert, 2012), 42. 
envidia formaron parte de aquellos años turbulentos, no solo como expresión o representación de subjetividades, sino como manifestación de lo social y lo político - por sus relaciones oblicuas con el poder, la dominación y la negociación-, el estudio de cartas y diarios escritos en aquellos años en Guatemala y otros países del istmo centroamerican, explora posibilidades para pensar la pertinencia de concebir todo el proceso nombrado hasta ahora como "conflicto armado interno" o "guerra" como una compleja totalidad que también fue -además de lo económico y político- una "estructura de sentimiento"3 en el plano cultural, que posibilitó, no únicamente en tanto ideologías y visiones del mundo en pugna, sino también en tanto experiencia afectiva de sujetos concretos, el surgimiento de ciertas formas que simultáneamente fueron sentimentales/axiológicas/ideológicas de época o generación, que afectaron indudablemente el arte -tema que no es el de este trabajo- y otras producciones como las textuales, incluso de carácter privado, porque afectaban el modo en que la subjetividad se enfrentaba a los acontecimientos en "tiempo real", es decir, en el curso mismo de su desarrollo.

Además de esta perspectiva más bien histórico-cultural, este estudio retoma el concepto de espacio biográfico de Leonor Arfuch, ${ }^{4}$ de raigambre sociológica y cultural, el cual permite el examen de estos textos como componentes de una vasta articulación de formas narrativas de vida que varían con el tiempo, en sintonía con el horizonte de su lectura. ${ }^{5}$ Siguiendo a Arfuch en el uso del concepto acuñado por ella, podemos señalar que el interés actual en la afectividad, como vía de exploración de la cultura, va fácilmente de la mano del interés en los géneros discursivos que con mayor cercanía e insistencia la trabajan: los autobiográficos. Interés que involucra no solo a los textos mismos, a su referencialidad autorial, a ese "yo" de la enunciación o a la construcción del "yo" del enunciado; sino también a su lector, el "otro" que cierra el círculo del espacio biográfico de cada época. Y es biográfico y no autobiográfico porque resulta de la coincidencia espacio temporal de las modalidades diversas de discursos y formas en las prácticas narrativas de vida - más allá de la autobiografía-, en conjunción con las modalidades diversas de su lectura y consumo en un sentido histórico-cultural. Concibiendo así las narrativas de vida de la guerra en Centroamérica - entre ellas las cartas y diarios- se facilita

3 Raymond Williams, Marxismo y literatura (Barcelona, España: Península, 1998).

4 Leonor Arfuch, El espacio biográfico. Dilemas de la subjetividad contemporánea (Buenos Aires, Argentina: Fondo de Cultura Económica, 2002).

5 Ana Lorena Carrillo y Socorro Gutiérrez Magallanes, Historia y espacio biográfico. Diarios $y$ cartas de guerra y exilio en Guatemala (Ponencia presentada en el Coloquio "Violencia y literatura en Guatemala", Universidad Autónoma del Estado de México, Sede Amecameca, 19-20 de mayo de 2016, inédito). 
la salida del círculo aislado del testimonio, de los límites personalizados y de estrechez genérica de la autobiografía y las memorias, así como del posible reduccionismo morboso de los diarios y las cartas.

El interés en diarios y cartas obedece a su condición de textos de intimidad escritos por sus autores o autoras, sin la mediación de un tercero, lo que supondría, por definición, dos presupuestos: una mayor "sinceridad" en la autodefinición subjetiva y un contexto social casi siempre situado en sectores medios e instruidos, con cierta formación intelectual más o menos homogénea. Estos supuestos, sin embargo, se quiebran al comprobar que un diario, como cualquiera otra modalidad textual en primera persona, no garantiza sinceridad ni objetividad, aunque se produzca sin intermediarios, aunque emerja de condiciones contextuales críticas y aunque sus destinatarios sean el propio autor o una sola persona; y que el diario, al igual que la carta, es también una práctica escritural, aunque rara, en sectores populares rurales de baja instrucción, si bien su función puede ser distinta. ${ }^{6} \mathrm{El}$ interés está puesto entonces, precisamente, en las modalidades mediante las cuales operan estos quiebres. Un presupuesto más se perfila en la investigación sobre estos temas: el diario y la carta directamente relacionados con temas del conflicto armado son prácticas escriturales evasivas. No solo se trata de formas que ponen en juego la discreción porque exponen la intimidad, sino que ello se agrava en contextos de violencia que reduplican el silencio, el secreto y la desconfianza. ${ }^{7}$ Es posible que muchos de estos documentos hayan sido destruidos, se mantengan celosamente guardados o simplemente que se trate de prácticas poco frecuentes. Este hecho ya lo había detectado Irina Bajini ${ }^{8}$ de la Universidad de Milán, quien tuvo que abandonar su proyecto sobre diarios de guerrilleras

6 En la investigación que actualmente realizo sobre estos temas, he analizado los diarios de Ignacio Bizarro Ujpán y Tomás Choc, campesinos. Dichos materiales contradicen el supuesto de que el diario es un género cultivado por intelectuales. La mención de un diario de veintiséis páginas escrito por Rubén Chanax Sontay, ex soldado, informante y testigo protegido del asesinato de monseñor Juan Gerardi en 1998, aún bajo la inercia de la guerra, aunque ya bajo los Acuerdos de Paz de 1996, está consignado con todas sus faltas ortográficas en el reportaje/novela El arte del asesinato político, de Francisco Goldman. Aunque no podemos asegurar que el documento exista realmente pues no se dan detalles de su ubicación, subrayamos el recurso al género diarístico y el escaso dominio de las reglas del código escritural y la baja escolaridad de sus autores en los ejemplos señalados. Francisco Goldman, El arte del asesinato político. ¿Quién mató al obispo? (Barcelona, España: Anagrama, 2013).

7 Linda Green, El miedo como forma de vida. Viudas mayas en la Guatemala rural (Guatemala, Guatemala: Ediciones del Pensativo, 2013), 71-72.

8 Irina Bajini, "Morir sin escribir o escribir para no morir. Diarios y testimonios de guerrilleras latinoamericanas (1970-2009)", en: Más allá del umbral. Autoras hispanoamericanas y el oficio de la escritura, (eds.) Silvana Serafin, Emilia Perassi, Susanna Regazzoni, Luisa Campuzano (Sevilla, España: Colección Iluminaciones, 61, Editorial Renacimiento, 2010). 
latinoamericanas en las últimas décadas del siglo XX por falta de material, pues las mujeres combatientes que inician un diario -dice- fracasan en su propósito, ${ }^{9}$ incluso si se trata de "diarios de campaña". La hipótesis de Bajini es que tanto la enorme cantidad de energía desplazada hacia la adaptación a situaciones de extrema vulnerabilidad en la guerrilla como la exigencia de con-fusión de la individualidad al proyecto colectivo hacen inviable la reflexión íntima de la propia subjetividad. No obstante, haciendo un reclamo feminista, Bajini se extraña de la existencia, resguardo, publicación y amplia circulación de diarios escritos por hombres en iguales circunstancias, desde notables hasta rangos menores en la jerarquía guerrillera. Aunque la búsqueda emprendida por mí no ha podido agotar todas las posibilidades, la escasez de diarios y cartas ha sido equilibrada con la flexibilización del criterio genérico, en parte debido a la idea de espacio biográfico ya comentada antes, y a la consideración elemental de la virtual imposibilidad de la pureza de géneros y formatos. Lamentablemente, la presentación de solo dos ejemplos en este artículo, que es lo que el espacio permite, no es suficiente para dar idea cabal de estos marcos conceptuales y su operatividad; lo que esperamos conseguir, en su momento, con una investigación más amplia.

\section{Afectos, sentimientos y afectividades en Centroamérica. estado de la cuestión}

La investigación sobre afectos, sentimientos y formas narrativas orales o escritas durante la guerra en Centroamérica tiene antecedentes dispersos. En su estudio pionero, publicado por primera vez en inglés en 1999 y en español catorce años después, la antropóloga Linda Green ${ }^{10}$ focaliza el miedo como un modo de vida entre las viudas de guerra de una comunidad rural guatemalteca. Habla de un miedo estructural colectivo, que forma parte de la historia nacional y local, la cultura y los modos de sobrevivencia. Green, quien cita a Raymond Williams, David Harvey y Stuart Hall entre otros, adopta en su mirada etnográfica la óptica de los estudios culturales de tradición marxista. El miedo, el terror, no es para Green tanto una emoción o sentimiento subjetivo como un "estado", una condición colectiva más cultural y política que psicológica, que resulta de la exposición prolongada, constante y ubicua de la violencia, la vigilancia y la ambigüedad de las amenazas latentes del entorno. El estudio de Green se establece en el campo de la cultura y no en la psicología social o en el material lingüístico. El de Green es un estudio de la estructura cultural, simbólica, histórica y funcional del miedo como política de Estado y como reacción individual y colectiva a la vez.

9 Ibid, 259.

10 Green, 2013. 
Emma Chirix ${ }^{11}$ estudia la afectividad de las mujeres mayas, definiendo afectividad o afecto como concepto antagonista del de violencia. ${ }^{12}$ Afectos, sentimientos y emociones son explorados a partir de entrevistas a mujeres mayas con una perspectiva que prioriza la subjetividad como centro de imantación y producción de las emociones. ${ }^{13}$ Chirix parte del presupuesto feminista para situar conceptualmente el universo sentimental y emocional -afectivode las mujeres mayas como históricamente construido a partir de la diferencia de género. ${ }^{14} \mathrm{El}$ afecto o la afectividad, entendidos como amor, cariño, aprecio dados y/o recibidos o no en los entornos familiar y laboral, así como los sentimientos de humillación, desprecio, dolor y su vivencia a partir del entorno racista de la sociedad guatemalteca, constituyen el centro del trabajo de Chirix, que no está situado temporalmente en el periodo del conflicto armado en Guatemala pero que se orienta -desde un enfoque psicológico social y etnográfico- a contribuir a procesos terapéuticos y de sanación de traumas producidos por él.

Ana María Cofiño ${ }^{15}$ trabajó los sentimientos de las mujeres kaqchikeles en la exhumación -entre 2003 y 2005- de cuerpos de víctimas de masacres cometidas por el ejército de Guatemala durante sus incursiones punitivas en San Juan Comalapa, Chimaltenango, durante el conflicto armado. Sin aludir a ningún "giro afectivo", como tampoco lo hace Chirix, Cofiño establece el estudio de las emociones, sentimientos o afecciones partiendo de la lectura de Spinoza, del que recupera, junto a la teoría y antropología feminista -aunque con mucho mayor peso de estas últimas-, la noción de cuerpo y la integridad cuerpo-emociones. Cofiño enfatiza, como también lo hace Chirix, en el carácter patriarcal de la configuración sentimental de las mujeres, aunque reconoce también la impronta sociocultural más general: clase, etnia, educación. En su estudio de los sentimientos de las mujeres kaqchiqueles, estos se exploran en una perspectiva etnográfica de amplio espectro y no centrada en el momento de la exhumación, con lo que permite un acercamiento general y descriptivo de las emociones -dolor, tristeza, alegría, etc.- desde la perspectiva lingüístico-cultural del otro.

11 Emma Delfina Chirix García, Alas y raíces. Afectividad de las mujeres mayas (Guatemala, Guatemala: Grupo de Mujeres Mayas Kaqla, 2003).

12 Ibid, 24.

$13 \mathrm{Ibid}, 30$.

14 Ibid, 29.

15 Ana María Consuelo Cofiño Kepfer, A flor de piel. Aproximación etnográfica a los sentimientos de las mujeres kaqchiqueles en la exhumación de San Juan Comalapa, Chimaltenango (2003-2005) (Tesis de Licenciatura en Antropología, Universidad de San Carlos de Guatemala, Escuela de Historia, Área de Antropología, octubre 2007). 
Afectividad y espacio biográfico en Centroamérica. dos cartas de guerra y exilio

El trabajo de Olga Alicia Paz Bailey ${ }^{16}$ aborda, a partir de una investigación cercana a lo etnográfico, el tema de la violación sexual de mujeres indígenas desde una perspectiva psicosocial. Los temas de la afectividad y los sentimientos se enmarcan en el contexto de la cultura local, los usos y costumbres. Miedo, vergüenza y susto son situados como expresiones que resultan de la conjunción de los hechos y experiencias de violencia sobre el cuerpo y la psiquis por un lado, y los patrones de la cultura local por otro. El silencio y la enfermedad, que según lo señala el estudio resultan de la experiencia traumática, se analizan como inscripciones corporales del daño sufrido, que se elabora a través de los filtros de la propia cultura como única estrategia posible para la sobrevivencia. La cultura resulta ser tanto el marco axiológico que acrecienta la gravedad de los efectos de lo sucedido, por ser esos hechos una violencia a los valores establecidos, como el único referente posible para crear estrategias que hagan posible sobrellevar la experiencia. Este estudio, centrado en los hechos específicos de las violaciones, coincide en algunos puntos con los precedentes de Ana Cofiño y Emma Chirix en el acercamiento a la definición de los sentimientos en el contexto de la cultura maya de Guatemala. Como puede observarse la mayoría de los estudios sobre emociones, sentimientos y conflicto armado, al menos en Guatemala, se han realizado en comunidades indígenas y con un enfoque etnográfico y sincrónico en que el marco histórico y procesual se limita a la evocación del recuerdo o la memoria individual de la experiencia, sin desarrollar con amplitud conceptos provenientes de la teoría de los afectos, ni proponer la posibilidad de una "estructura" sentimental o emocional diacrónica, con la excepción de Linda Green. Es notorio que ni emociones, ni sentimientos ni afectos se estudian con igual interés en la población ladina de este país, que también sufrió en los centros urbanos y especialmente en la Ciudad de Guatemala los devastadores efectos de la guerra y donde las víctimas y familiares también se organizaron para enfrentar el desamparo, también acudieron a exhumaciones y reconocimiento de cadáveres a la morgue y vivieron la angustia, el miedo y la soledad de la clandestinidad o el exilio propio o de otros miembros de la familia. La perspectiva de la emocionalidad -que no necesariamente los afectos-de las víctimas, que es privilegiada en los estudios anteriormente señalados, ofrece una interesante veta de conocimiento acerca del conflicto armado, pero debe considerarse que tal perspectiva conlleva un componente persuasivo importante que coloca desde el inicio al investigador y al lector "del lado" de las víctimas a partir de

16 Olga Alicia Paz Bailey, "Violencia, cuerpo y sociedad. Efectos físicos y psicosociales de la violación sexual durante el conflicto armado en Guatemala", en: Crisis, sociedad civil y memoria en América Latina, (ed.) Blanca Laura Cordero Díaz y Octavio Humberto Moreno Velador (Puebla, México: Benemérita Universidad Autónoma de Puebla, Instituto de Ciencias Sociales y Humanidades, 2014). 
la empatía que se quiere establecer con la perspectiva ideológica y la normativa ética y moral de los sujetos. Los tres estudios mencionados, sin embargo, podrían ser considerados antecedentes en el estudio de la afectividad en la línea de lo que Enciso Domínguez y Lara consideran la "precuela" del "giro afectivo" en el orden de lo que los estudios culturales, las emocionologías y los estudios feministas han aportado al respecto. ${ }^{17}$

José Domingo Carrillo ${ }^{18}$ en su artículo "El amor en los tiempos de guerra. Afectos y desafectos en la literatura testimonial centroamericana" escoge una perspectiva crítica que podría llamarse -usando la terminología de Juan Duchesne Winter-, ${ }^{19}$ heteronormativa, como se verá a continuación. Carrillo propone el acercamiento al sentimiento amoroso y sus rituales y prácticas dentro de la insurgencia, a partir de la revisión de distintos materiales testimoniales. ${ }^{20}$ No se trata aquí de "traducir" las palabras de los sentimientos del otro expresadas en su idioma, tampoco de estudiar patologías sociales, ni de explorar modos de expresión de sentimientos como vía terapéutica. El énfasis historiográfico del artículo, situado en la historia cultural, pone la atención en los pasajes de los textos en que se hace referencia a relaciones amorosas -en todos los casos heterosexuales- dentro de narrativas testimoniales más amplias, dando cuenta de enamoramientos, noviazgos, bodas, prácticas sexuales y de reproducción, al interior de las organizaciones revolucionarias centroamericanas. Carrillo destaca la paradoja que supone la continuidad, en la mayoría de aquellos rituales y prácticas, de las formas consagradas por la institucionalidad, sea Iglesia, Estado o costumbre, en el seno de las organizaciones que luchaban por echar por tierra aquella institucionalidad. De igual manera destaca la subordinación del sentimiento amoroso a la lealtad militante que operaba en las organizaciones guerrilleras. El sentimiento amoroso al igual que sus rituales, aunque se inscriben en un código conductual e ideológico rebelde, terminarían por reproducir el concepto burgués del amor romántico que por cierto anima no solo la pasión erótica sexual, sino al sentimiento "patriótico"

17 Giazú Enciso Domínguez y Ali Lara, "Emociones y ciencias sociales en el s. XX: La precuela del giro afectivo", Athenea Digital (Barcelona) 14, n. 1 (marzo 2014): 263-288, DOI: https://doi.org/10.5565/rev/athenead/v14n1.1094.

18 José Domingo Carrillo, "El amor en tiempos de guerra: afectos y desafectos en la literatura testimonial centroamericana", Revista Latinoamericana de Estudios sobre Cuerpos, Emociones y Sociedad (Argentina) 11 (abril-julio 2013): 83, URL: http://www.relaces.com.ar/ index.php/relaces/article/viewArticle/186.

19 Juan Duchesne Winter, La guerrilla narrada. Acción, acontecimiento, sujeto (San Juan, Puerto Rico: Ediciones Callejón, 2010).

20 El corpus estudiado incluye textos de Claribel Alegría, Omar Cabezas, Yolanda Colom, Julio César Macías, Pedro Palma Lau, Mario Payeras, Miguel Ángel Sandoval y testimonios nicaragüenses recogidos por Margaret Randall. 
y la pasión política que tantas veces fue motivo primordial de los poetas guerrilleros en estricta simetría con aquella. El artículo deja planteado el vacío de información sobre el amor homosexual en la guerrilla, tema tabú aún vigente, a pesar del largo proceso de reconfiguración ideológica a los tiempos de paz entre los exmilitantes y simpatizantes; proceso que, sin embargo, ha dejado incólumes, en la mayoría de los casos, sus percepciones del heroísmo, la épica viril y el consiguiente concepto tradicional de la masculinidad.

Carrillo aborda someramente en este artículo, y en profundidad en otro distinto, ${ }^{21}$ las actitudes ante la muerte en la guerrilla guatemalteca y de alguna manera ambos trabajos se articulan en torno a dos figuras generadoras de sentimientos, pasiones y afectos: Eros y Thanatos, inscribiéndolas en un marco cultural y social. En El Salvador, en cambio, parece haber más apertura para hacer un balance retrospectivo del amor homosexual en la guerrilla, que deja ver que también en aquel tiempo hubo una relativa flexibilidad. ${ }^{22} \mathrm{El}$ tema resulta crucial porque de él depende el cuestionamiento o no de uno de los presupuestos fundamentales de las diferencias de género: la asignación de ciertos sentimientos a cada uno de ellos. De esta suerte, el concepto tradicional de masculinidad, incuestionado en periodo de guerra, incluye la atribución a los hombres de una sensibilidad controlada, con ausencia de formas de "debilidad" emocional, usualmente asignadas a las mujeres. Un concepto de masculinidad que se construye en cambio con una fuerte interdicción sobre aquellos sentimientos asociados al llanto $;^{23}$ lo que por cierto, en el contexto de la guerrilla, suele ser exigido o autoimpuesto también en las mujeres militantes. La homosexualidad entonces representa un quiebre en dicha idea. Son los estudios de género y los literarios los que más se acercan a dicha temática desde una perspectiva crítica. Es a partir del desmontaje de la visión heroica y de los modelos de autoridad de la guerrilla que realizan las novelas, que puede

21 José Domingo Carrillo, "Las actitudes ante la muerte: testimonios de los movimientos armados guatemaltecos", en: Etnia, género y clase en el discurso y la práctica de las izquierdas de América Latina, (ed.) Miguel Ángel Urrego y José Domingo Carrillo (San Luis Potosí, México: Universidad Autónoma de San Luis Potosí-Universidad Michoacana San Nicolás de Hidalgo, 2012), 253.

22 Amaral Palevi Gómez Arévalo, "Del 'cuiloni' al homosexual: sexualidades masculinas disidentes en El Salvador entre 1932-1992”, Cultura, Lenguaje y Representación (España) 15 (2016): 119-137, DOI: http://dx.doi.org/10.6035/clr.2016.15.8.

23 Para una discusión del tema de la masculinidad, el llanto y la militancia, ver el artículo de Ana Peluffo, en el que se discute con amplitud la novela de Alan Pauls, Historia del llanto. Un testimonio. Véase: Ana Peluffo, "Emoción, afectividad y sentimiento en la construcción del pasado setentista", en: El lenguaje de las emociones. Afecto y cultura en América Latina, (eds.) Mabel Moraña y Antonio Sánchez Prado (Madrid, España: Iberoamericana; Vervuert, 2012). 
llegarse al tema de la masculinidad y los afectos. A partir de la producción literaria el tema ha sido destacado por la crítica, ${ }^{24}$ aunque no necesariamente poniendo en el centro los sentimientos y la afectividad, como es el caso del trabajo de Albino Chacón ${ }^{25}$ sobre la novelística reciente centroamericana - parte de ella de tipo testimonial- y la crisis de los modelos de autoridad del proyecto guerrillero.

Juan Duchesne Winter en La guerrilla narrada hace un examen de testimonios guatemaltecos y de otros países latinoamericanos - Cuba y Argentina- configurando un verdadero espacio biográfico guerrillero. Si bien Duchesne no se guía por las teorías de la afectividad, recala inevitablemente en el tema a partir de la necesaria relación entre los sentimientos y la ética. ${ }^{26}$ Desde su distinción de los testimonios como normativos o heteronormativos, Duchesne revisa textos autobiográficos creando la posibilidad de su lectura crítica en el orden sentimental. Patricia Alvarenga ${ }^{27}$ en su trabajo "El sujeto revolucionario en Roque Dalton" pone en evidencia, a partir de la narrativa

24 Erick Aguirre, sin citar la fuente, señala un trabajo de Werner Mackenbach, "para quien, además, el tema de la sexualidad, el tabú de la homosexualidad, la hiriente y a veces irónica crítica del machismo o la inseparable amalgama de sexualidad y violencia, ocupan un amplio espacio en la narrativa de muchos nuevos autores [...]". Erick Aguirre, "Novelando la posguerra en Centroamérica", Istmo. Revista Virtual de Estudios Literarios y Culturales Centroamericanos (Nicaragua) 9 (julio-diciembre 2004), URL: http://istmo.denison.edu/ n09/foro/novelando.html. Por otra parte, una crítica de corte más convencional pero erudita, discute la condición "cínica" de la narrativa actual y reposiciona las novelas recientes en el istmo dentro de una vuelta a la tradición picaresca proponiendo una interpretación clásica del cinismo como "quinismo". Véase de Emiliano Coello Gutiérrez, "El discurso crítico sobre el cinismo en la novela centroamericana contemporánea. Bases para una lectura alternativa", Convivencia (Panamá) 1 (2014): 31, disponible en URI: http://www. cervantesvirtual.com/nd/ark:/59851/bmcvm660.

25 Albino Chacón Gutiérrez, "Modelos de autoridad y nuevas formas de representación en la literatura centroamericana", Letras. Revista Electrónica de Literatura y Ciencias del Lenguaje (Costa Rica) 1, n. 49 (2011): 13, URL: http://revistas.una.ac.cr/index.php/letras/ article/view/5221.

26 Para un análisis de la ética como educación emocional y consecuentemente de virtudes y valores aplicado a la actualidad y fundamentado en conceptos filosóficos, véase entre otros, José Antonio Marina, "Precisiones sobre la educación emocional", Revista Interuniversitaria de Formación del Profesorado (España) 19, n. 3 (diciembre 2005): 27-43, URL: http:// www.aufop.com/aufop/revistas/arta/impresa/19/66/. Sobre la construcción de una ética particular de la militancia socialista, comunista y guerrillera en América Latina, si bien existen ya algunos trabajos, queda todavía mucho por hacer.

27 Patricia Alvarenga Venutolo, "El sujeto revolucionario en Roque Dalton", Cuadernos Inter.c.a.mbio sobre Centroamérica y el Caribe (Costa Rica) 9, n. 10 (2012): 183, URL: http://revistas.ucr.ac.cr/index.php/intercambio/article/view/2981. 
transgresora del poeta, que sin duda puede ser leída en clave autobiográfica, ${ }^{28}$ la tensión contradictoria y hasta irreconciliable que atraviesa la voz narrativa en algunos de sus textos, por ejemplo, la dialéctica de lo racional/emocional y la dualidad amor/odio - a la patria, a los salvadoreños-, así como la paradoja de su ordenamiento sentimental masculino tradicional y la gama variada de emociones que recorre su obra y voz poética. Sin abordar la obra de Dalton desde la teoría de la afectividad, el trabajo de Alvarenga da pie para pensar en el papel iconoclasta de este "mosaico" emocional en medio de una "cultura política" caracterizada por el control de las emociones y de un contexto político de represión y "activismo de alto riesgo". ${ }^{29}$ Sin agotar siquiera una primera revisión de la bibliografía existente, pero intentando dar cuenta de algunos de los temas o enfoques que se están abordando en Centroamérica para tratar el periodo de los conflictos armados desde los sentimientos, la afectividad y el espacio biográfico, puede concluirse sin embargo, que si bien el giro afectivo no es una referencia teórica y conceptual importante en estos estudios, ${ }^{30}$ la

28 María del Socorro Gutiérrez Magallanes, Autobiografía politica chicana y latinoamericana: una producción cultural contrahegemónica. Proyectos culturales que revelan, procesos sociales que difieren y estructuras que convergen (palabras, vidas y utopías de Gloria Anzaldúa y Roque Dalton) (Tesis de Doctorado en Ciencias Políticas y Sociales, Universidad Nacional Autónoma de México, 2014).

29 Las emociones relacionadas con los movimientos sociales son: a) emociones reflejas como el miedo, la ira, la alegría y la tristeza; b) emociones afectivas como el amor, odio, respeto y confianza; c) emociones morales como orgullo, vergüenza, culpa, indignación, envidia y; d) ambientes emocionales como esperanza, ansiedad, depresión, melancolía. El activismo de alto riesgo, como el que se realiza en la clandestinidad, está estudiado para el movimiento anarquista en la España franquista, al igual que las categorías de emociones, en el artículo de Eduardo Romanos, "Emociones, identidad y represión: el activismo anarquista durante el franquismo", Revista Española de Investigaciones Sociológicas (España) 134 (abril-junio 2011): 87-106, DOI: http://dx.doi.org/10.5477/cis/reis.134.87. El acercamiento al estudio de las emociones y la afectividad a partir de las narrativas de la guerrilla centroamericana tiene sin duda un valioso referente en el libro de Ileana Rodríguez Women, Guerrillas and Love. Understanding the War in Central America, de 2004, pero se trata de un texto que no estoy en condiciones de comentar aquí.

30 Trabajos de Chirix y Paz Bailey son mencionados en el prólogo a la traducción al español de la obra de Sara Ahmed, La política cultural de las emociones, publicada en 2015; obra que es considerada ahí como una de las más influyentes del llamado "giro emocional". No obstante, los trabajos de Chirix, Cofiño y Paz Bailey revisados aquí no citan a Sara Ahmed ni a otros autores como Brian Massumi, Graco y Stenner o Lauren Berlant, considerados referencias principales del llamado "giro afectivo". En el caso de Chirix y Paz Bailey, la autora del prólogo considera que se trata de trabajos que si bien ponen en el centro el cuerpo, lo hacen situándose desde una posición crítica decolonial, es decir, que no asumen una epistemología eurocéntrica. Personalmente, pienso que el trabajo de Chirix no podría haber citado a estos autores en sus obras clásicas no por otra razón sino porque se publicaron después. Cofiño solo podría haber citado a Berlant por las mismas razones. En cuanto a Paz 
afectividad, las emociones y los sentimientos son objeto importante de análisis y se examinan desde perspectivas diversas, casi siempre mediadas por la cultura. En el análisis que sigue, intento continuar en esa línea, rastreando las huellas de la afectividad en cartas, una de las modalidades de los géneros autobiográficos, pero también una suerte de objetos de memoria que forman parte del archivo y del espacio biográfico de los conflictos armados centroamericanos de los años setenta y ochenta del siglo pasado. El intento de situarme simultáneamente como lectora crítica de los textos estando implicada y siendo interpelada afectivamente por ellos supone un reto que mi perspectiva epistemológica desde la crítica cultural está en condiciones de asumir, aunque el resultado final quede sujeto a los riesgos que de ello se derivan.

\section{Sequía de palabras. Autocontrol y censura en cartas del conflicto armado - Del epistolario de Norma Padilla-}

Las dos cartas que analizo a continuación son piezas aisladas de un pequeño epistolario, lamentablemente incompleto, que cubre un periodo entre 1980 y 1983, que fueron años de muy alta conflictividad y violencia en Guatemala. Son cartas que me fueron enviadas por una mujer urbana de clase media intelectual, Norma Padilla (1930-1984), a mí, su hija -y familia- en el exilio. Antes de entrar propiamente al texto, es importante puntualizar algunos conceptos fundamentales del análisis del discurso y la teoría sobre la estructura del género epistolar.

Desde el análisis del discurso el llamado "contexto" de una carta es social en el sentido de construido por los participantes durante la interacción discursiva. ${ }^{31}$ Desde este punto de vista, el contexto se entiende como las

Bailey, su trabajo claramente se sitúa en la perspectiva de la psicología social. Me parece arriesgada la posibilidad de considerar como decolonial la perspectiva epistemológica de trabajos como los analizados aquí de Chirix y Paz Bailey -cuya bibliografía se nutre ampliamente de autores y metodologías "occidentales" y no hacen crítica consistente de las mismas desde la decolonialidad-, solamente porque sus temáticas se refieren a poblaciones indígenas y en uno de los casos su autora lo es también, o porque analizan la afectividad a partir de las interpretaciones culturales y lingüísticas de las emociones propias de esas comunidades. Pienso que en esos trabajos, como en los de Carrillo, Chacón, Duchesne y Alvarenga que menciono, no se cita a los autores clásicos del "giro afectivo" porque o no tuvieron al alcance su obra y/o porque dicho "giro" como moda intelectual no está en sus intereses, como sí lo están en cambio las emociones como objeto de estudio antropológico, literario o histórico. Helena López, "Prólogo a la traducción al español de 'La política cultural de las emociones' de Sara Ahmed”, disponible en URL: https://goo.gl/rtNpBU.

31 Guillermo Soto Vergara, "La creación del contexto: función y estructura del género epistolar", Onomázein. Revista de Lingüistica, Filología y Traducción (Chile) 1 (1996): 152, URL: http://onomazein.letras.uc.cl/03_Numeros/N1/N1.html. 
condiciones inmediatas al texto, que posibilitan su producción. Se refiere al emisor y a ciertas situaciones relativas al evento comunicativo y al acto comunicativo, ${ }^{32}$ por ejemplo la referencia a otras cartas anteriores y/o referencias a información que, en la interacción cara a cara, sería accesible al receptor por medios extraverbales, como el clima o las características del lugar en que ocurre la interacción. Otros configuradores del contexto de emisión de la carta son por ejemplo las indicaciones de tiempo y lugar $-\mathrm{O}$ emplazamiento-; las apelaciones al destinatario -o saludo-, la identificación del emisor -generalmente como parte de la despedida- o la identificación de destinatarios mediatos - saludos a otras personas-. En la carta que se analiza se intenta poner en relación ese contexto discursivo de emisión inmediato con el contexto histórico-social.

La primera que analizamos es una carta manuscrita, fechada el 18 de junio de 1980, en cuya sección de emplazamiento solamente figura la fecha, sin indicación de lugar. Un elemento del contexto de producción de esta carta referente a la fecha es que se trata del día del cumpleaños de mi padre, es decir, una fecha con cierta carga afectiva particular, de lo que no se hace ninguna mención en el texto. El vocativo con el que inicia: "Mis queridos seres" señala ya a varios destinatarios y no uno como usualmente sucede con las cartas, rasgo repetido en casi todas las de este epistolario. Significativamente, el texto no incluye nombres propios, lo que puede interpretarse como la elaboración de un código comunicativo encriptado, que se despliega en el resto de la carta en previsión de que fuera leída o intervenida por otros. Inmediatamente después del vocativo se da paso a una introducción que de lleno aborda el tema de esta carta, que es precisamente la comunicación y la expresión, obviando marcadores contextuales que son recurrentes en la correspondencia, por ejemplo el esquema de tipo "Querido X hoy en la tarde me he decidido a escribirte". No importa en esta escritura de crisis -escasos ocho días después de un asesinato político sensible en la familia- mantener la codificación canónica. En la carta que aquí se analiza la estructura se altera dando lugar a un discurso epistolar desarticulado: "Mis queridos seres: Hasta la posibilidad de expresarme siento se me va secando, y cada vez más difícil la tan ansiada comunicación con todos, pero saben bien que los amo a los dos y que me ha dolido todo infinitamente".

La urgencia de hacer de la carta vehículo inmediato de afectos y emociones construye una estructura textual atípica. Lo primero que se enuncia es ciertamente el contexto de emisión del discurso, como pide la forma "carta", pero se hace de modo no convencional al referirlo a los bloqueos expresivos.

32 Miguel Ángel Farías Farías, "Leyendo entre cartas. Análisis discursivo de algunas cartas de Violeta Parra", Logos: Revista de Lingüística, Filosofia y Literatura (Chile) 2 (1990): 31, URL: http://revistas.userena.cl/index.php/logos/article/view/241. Soto, 1996. 
De hecho, es frecuente en cartas y crónicas de exilio la mención a un bloqueo de palabras o sentimientos que se atoran, no salen, se secan o se truncan. Lo que se dice es precisamente que no es posible decir. La separación física impuesta, muchas veces antecedida de hechos violentos, como en el caso de esta carta, afecta significativamente el flujo verbal. No solo en el sentido del cambio de comunicación oral a comunicación escrita, sino en el de grave perturbación de la interacción comunicativa, tanto en el nivel corporal-lingüístico -"la posibilidad de expresarme se me va secando"- como en el social-(con) textual -"y cada vez más difícil la tan ansiada comunicación con todos"-; perturbación que se remite tanto a algo que está más allá o fuera del sujeto y del texto, como al sujeto mismo. Es la posibilidad de la expresión lo que se seca, una "posibilidad" que está dada -y eventualmente restringida- por el contexto social y personal de enunciación. La "posibilidad" de expresión existe como algo social y también personal, pero el "hasta" del enunciado sintetiza una serie continuada de restricciones que se metaforizan como secamientos o sequedades, es decir, como muertes. La ambigüedad de la frase permite suponer que la "sequía" obedece tanto a un designio externo como a uno interno, como podría ser una autocontención emocional que evita el desborde, idea que se refuerza con el cambio abrupto del hilo discursivo: “...y cada vez más difícil la tan ansiada comunicación con todos". La comunicación -"con todos"-, que el sujeto nombra como "ansiada", es "cada vez más difícil" y nuevamente la ambigüedad deja sin definir la causa de la dificultad, que podría ser externa, o nuevamente, interna, del sujeto mismo. La perturbación real en el flujo comunicativo y en la estructura textual se manifiesta en un discurso ambiguo y entrecortado, que en esta parte introductoria plantea la perturbación en los dos niveles ya señalados -el corporal-lingüístico y el social-(con)textual- y uno más: el propiamente afectivo de la descarga sentimental que funciona como afirmación y a la vez liberación de los dos bloqueos previos, dando lugar a la manifestación amorosa y solidaria abierta: "pero saben bien que los amo a los dos y que me ha dolido todo infinitamente". Sin embargo, el enunciado también da lugar a nuevas codificaciones con el uso del deíctico "todo" que funciona como dispositivo de autocensura que regula estrictamente el contenido y la propia comunicación.

El conflicto armado, y una de sus consecuencias, el exilio, no solo separó físicamente, sino que impuso una nueva forma de relación entre personas ligadas afectivamente: confiscó su derecho individual a la comunicación libre imponiendo la distancia y los controles policiales a la correspondencia, que obligaron a tiempos largos de silencio, autocensura e incomunicación. Más aún, el terror obligó a que la separación física entre miembros de una familia lo que podía ser sospechoso en el entorno social- fuera asumida públicamente 
por los que se quedaban en el país con versiones desinformadoras y falsas, a veces pactadas entre los miembros de la familia involucrada y a veces, en su peor versión, impuestas por unos a otros, como se relata en las cartas clandestinas de Lil Milagro Ramírez compiladas por Medrano, ${ }^{33}$ o las de Roque Dalton estudiadas por Castellanos Moya $^{34}$ de El Salvador o las crónicas de exilio de Elena Paz y $\mathrm{Paz}^{35}$ de Guatemala. Así pues, el terror y la separación física impuesta por las circunstancias -exilio o clandestinidad- son dos situaciones clave del contexto histórico afectivo de producción y enunciación de estas escrituras de la intimidad en la guerra.

En los textos esto se presenta como desestabilización de la estructura lingüística a modo de balbuceos o el ya señalado bloqueo de palabras. La carta que citamos no narra acontecimientos; más bien se limita a informar. En una sola cuartilla y escrita por las dos caras, el tema de la misma se centra en asuntos prácticos para poder sostener comunicación telefónica urgente. Es decir, el cuerpo de la carta o narratio no narra; en su lugar opera una economía política del lenguaje bajo terror y violencia. La función comunicativa se desdobla en reflejo especular al referirse a la comunicación misma, como si en esto se apostara también la continuidad de la vida; y de hecho, si se atiende a la metáfora de la sequía o secamiento, la comunicación se convierte, de hecho, en su contrario: florecimiento, vida, expresión. Dicho de otro modo, la iteración y reiteración destacan la vulnerabilidad del vínculo comunicativo. El carácter urgente de la situación extratextual tiene su réplica en la del evento comunicativo y esta en el diseño interior del mismo.

Un breve párrafo refiere al estado de un miembro de la familia especialmente vulnerable por ser un menor, así como del resto de la familia, aunque se hace sin detenerse en la narración de acontecimientos, ni mencionar nombres propios en parte alguna de la carta. Nuevamente marcado por deícticos que señalan sin nombrar, el discurso muestra la fractura en la comunicación y en el discurso que debe apelar a indicadores vagos que deben ser decodificados en la lectura por los destinatarios:

33 Miriam Medrano (compilación y textos), Lil: milagro de la esperanza. Cartas y poemas (San Salvador, El Salvador: Laberinto Editorial, 2013).

34 Horacio Castellanos Moya, "Dalton: correspondencia clandestina (1973-1975)", Iowa Literaria, 4 de noviembre de 2013, URL: http://thestudio.uiowa.edu/iowa-literaria/?p=2119.

35 Elena Paz y Paz, Ya no tengo palabras (Guatemala, Guatemala: Editorial El Pensativo, 1997). 
"Ha estado muy bien, contento y sin problemas. De lo demás, nuestro amigo seguro que tendrá ratos para platicarles y ustedes se alegrarán como todos de las cosas cotidianas de la familia.

¿Qué más decirles? No sé, ni puedo, cuídense mucho, espero y tengo fe en que todo saldrá bien para todos, con amor y mil besos,N". ${ }^{36}$

Las emociones, afectadas por el conflicto, si bien se relacionan con el cuerpo, tienen una relación privilegiada también con la palabra. La palabra o la falta de ella son territorios en que recalan cuerpo y subjetividad; cuerpo y emociones; cuerpo y afectividad. El silencio es, sin duda, el mecanismo simbólico por excelencia que concentra tanto el acto de cerrar la boca como la experiencia emocional del miedo, la vergüenza, la culpa y otras. Para la clase media intelectual urbana de Guatemala en los años del conflicto, el dolor y la preocupación se resuelven inicialmente en silencio, que funciona como estrategia de sobrevivencia, a la vez que de instrumento de represión ${ }^{37}$ según sea voluntario o impuesto; aunque en un segundo momento, la escritura se constituye en válvula de escape y estrategia de subversión frente a la imposición del silencio por el poder. No obstante, ni así la escritura escapa completamente a la contención represiva y a la incapacidad de decir o "empalabrar" la experiencia de la crisis: "¿Qué más decirles? No sé, ni puedo" se dice en esta carta que, hecha llegar a sus destinatarios por mano, evade la posible vigilancia. El deseo de restablecer los lazos afectivos/familiares rotos por la separación por exilio o clandestinidad es una constante que no solo se muestra en la utilización de la comunicación epistolar, sino en el uso de un lenguaje en ella que enfatiza en el vínculo, la unidad, el colectivo: "Mis queridos seres"; "ustedes se alegrarán como todos de las cosas cotidianas de la familia"; "todo saldrá bien para todos". Las manifestaciones verbales -y también las no verbales- del amor y la solidaridad como afectividades estratégicamente activadas en momentos de dificultad, suelen instalarse en la memoria y reproducirse en cualquier circunstancia parecida posterior. En términos conductuales, la respuesta afectiva a una repetición de condiciones similares a las vividas antes, de extrema tensión, temor y violencia, se aprende y se replica junto a su manifestación verbal. Tanto el miedo y la angustia como el amor y el consuelo experimentados se enraízan en la memoria afectiva. ${ }^{38}$ No obstante es importante consignar que

36 Carta 18 de junio 1980.

37 Antonius Robben C.G.M y Caroline Nordstrom, "Introduction", en: Fieldwork Under Fire. Contemporary Studies of Violence and Survival, Robben y Nordstrom (Los Ángeles, California, EE. UU.: University of California Press, 1995), 1.

38 En los estudios etnográficos mencionados antes, el tema del enraizamiento de los sentimientos 
desde la perspectiva psicoanalítica hay casos individuales de problemas con el manejo de los afectos, los sentimientos y la memoria en sujetos que han experimentado violencia política. La incapacidad para la empatía o la dificultad para sanar heridas narcisistas y elaborar adecuadamente el duelo ${ }^{39}$ contribuye a que la experiencia compartida del miedo y la violencia que produjo el conflicto armado, así como la del amor y la solidaridad, en lugar de crear actitudes de respeto, sentido colectivo y gratitud, ${ }^{40}$ crea "olvidos" y se traduce en resentimiento y victimización individualista perpetua; en duelo irresuelto. Para estas personas toda bondad emana de ellos como eternas víctimas y toda maldad de los victimarios originales y de todos aquellos en los que proyectan patológicamente aquel pasado ignominioso que, sin embargo, les otorga poder social, impunidad ${ }^{41} \mathrm{y}$ ventajas.

En otras cartas de este conjunto, correspondientes al mismo año 1980, los temas alternan entre relatos sobre lo que ocurre en las vidas de los miembros de la familia, lo que sucede en el país y los infinitos arreglos que requería apoyar desde dentro del país en dictadura y confrontación militar, a quienes afuera, en el exilio, debían organizar de nuevo la vida. Los objetos domésticos ${ }^{42}$ son un tema relevante que habla de la testaruda importancia que

ligados a la violencia y el terror es culturalmente significativo, como se demuestra para las mujeres mayas estudiadas por Cofiño y Paz Bailey. En el apartado autoetnográfico del estudio de Cofiño, ella reconoce que desde su propia condición sociocultural los efectos de la violencia en ella y la generación que la vivió son igualmente marcas indelebles en la memoria. Cofiño, 150.

39 La pertinencia de la relación entre el duelo nacional por la violencia y la elaboración del duelo en pacientes individuales está consignada en la interesante investigación de Iduar Dereix Calonge situada en Colombia: Heridas narcisistas: un impedimento para la elaboración del duelo (Tesis de Maestría en Psicología Clínica, Pontificia Universidad Javeriana, Bogotá, Colombia, 2014), URL: https://repository.javeriana.edu.co/.

40 Green, 106.

41 José Luis Lillo, "Sobre el perdón y la reconciliación. Una perspectiva psicoanalítica", Temas de Psicoanálisis. Revista de la Sociedad Española de Psicoanálisis (España) 7 (enero 2014): 1-35, URL: http://www.temasdepsicoanalisis.org/sobre-el-perdon-y-la-reconciliacion-una-perspectiva-psicoanalitica-2/.

42 Sobre los afectos -o "energía"- que emanan los espacios o que proyectan las subjetividades en espacios y objetos relacionados con experiencias de conflicto, desarraigo, abandono, el artículo de Yael Navaro-Yashin -"Objetos de violencia, espacios afectivos, zonas de ruina. Un estudio teórico de los ambientes de la posguerra", Bifurcaciones. Revista de Estudios Culturales Urbanos (Chile) 14 (2013), URL: http://www.bifurcaciones.cl/2013/10/ espacios-afectivos-objetos-melancolicos/- aporta sugestivas interpretaciones sobre el tema teórico de la relación entre psicología y sociedad en etnografía abordada desde un concepto de afecto o afectividad ligado al de "energía" y "melancolía". Navaro-Yashin introduce la metáfora de la "arruinación" para designar no solamente los objetos y espacios corroídos 
adquieren en un contexto en que salvarlos podía costar amenazas, como de hecho fue el caso, o hasta la vida; pero que encarnan la fuerza que obligó al quiebre del orden privado y la necesidad igualmente fuerte de recomponer lo quebrado, en este caso a partir de objetos de valor simbólico para este grupo social: empacar y mandar libros -aun siendo comprometedores-, vaciar un cubículo al que nadie quería entrar por miedo, enviar una máquina de escribir y una calculadora, vender mobiliario - carta del 27 de julio de 1980-. El dolor de la separación y el temor de los alcances de la represión, que ya había dado señales en la familia, figura en la carta del 24 de noviembre de ese mismo año, en que el tema -común en cartas de exilio y clandestinidad- de la "fachada" social se asume como estrategia de sobrevivencia familiar. En esta carta se representa a través de una suerte de performance lingüístico-verbal que "actúa" el duro contenido informativo para enfatizarlo y "efectuarlo":

“...lo único que podemos hacer tanto ustedes como nosotros es dar la fachada de que no existe ninguna relación, así, absolutamente ninguna, no sabemos nada de ustedes y no queremos saber. No sabemos dónde viven, en otras palabras no tenemos hijos, somos ajenos y enemigos de sus cosas y su vida. Si lo hacemos así, estrictamente, y lo regamos y no hay ningún contacto controlable creo que podemos aguantar". ${ }^{43}$

por el tiempo, la destrucción y el abandono, sino también los afectos que se generan en la circulación actualizada de dichos objetos y espacios. Su discusión sobre el tema epistémico que salta a la vista -el de si los afectos son proyectados por los sujetos en los objetos o si se generan en estos- involucra consideraciones sobre los modos actuales en la producción de conocimiento y, específicamente, una crítica a las metodologías que están desplazando el foco de interés de los humanos a los objetos y los espacios, que va mucho más allá de lo que aquí nos interesa. Quizá para fines de este trabajo baste con nociones como huella, vestigio o ruina como modo de asignar valor histórico o de proceso a lo que ocurre con/ en/ entre objetos y personas en contextos de violencia; como por lo demás lo hace finalmente Navaro-Yashmin, luego de un extenso recorrido teórico sobre la dicotomía abierta entre la propuesta deleuzeana -con raíces en Spinoza- que separa la afectividad de la subjetividad, el sujeto y el discurso, y por otro lado, las teorías sobre los afectos que mantienen la ligazón entre afectividad y subjetividad. La noción de "ruina", elaborada inicialmente por W. Benjamin parece más cercana a la reflexión sobre no solo los objetos, los enseres domésticos, íntimos y familiares que son evocados en los textos que analizamos, sino sobre los textos mismos, que desde su mismo origen son concebidos como testimonios, huellas o marcas en primera persona de la experiencia vivida en aquél tiempo y en aquel lugar.

43 Carta 24 de noviembre 1980. 
Afectividad y espacio biográfico en Centroamérica. dos cartas de guerra y exilio

Como puede verse con estos y otros ejemplos de escrituras de la subjetividad, la clase media intelectual experimentó la violencia y el terror a partir del quiebre o puesta en riesgo de sus referentes socioculturales significativos: familia, estabilidad, aspiraciones de ascenso social, consumo de bienes culturales y simbólicos. Todos ellos aspectos que, si bien son importantes en general, adquieren especial relevancia para los sectores medios. No existen ya las cartas que respondieron a las aquí citadas. Su lectura habría completado el ciclo comunicativo y con ello se habría avanzado en la definición del contexto discursivo. Sin embargo, en términos puramente emocionales, el efecto del párrafo citado arriba fue devastador. Aun sabiendo que se trataba de una estratagema concebida para atenuar la vigilancia, era imposible evitar el dolor y la indignación generados por la certidumbre de que esta "actuación" - mi madre era actriz por lo demás-, respondía a un designio perverso que obligaba a efectuarla. Vigilancia, castigo, poder y régimen de control de los cuerpos y los afectos en esta pequeña muestra de intersección de política, emociones y textualidades autobiográficas.

El quiebre de sus marcos de referencia y la confrontación explícita con la ira y la injusticia y/o la experiencia de la solidaridad ${ }^{44}$ en el ámbito familiar podrían ser factores afectivos relevantes a ser tomados en cuenta para evaluar por ejemplo, entre otros asuntos, el grado de participación, simpatía o rechazo que la clase media no militante manifestó en los procesos relacionados con el conflicto armado que tenía lugar en la región; es decir para realizar, con una perspectiva abierta, un acercamiento a dicho periodo que contemple, junto a los otros factores decisivos, la afectividad y sus manifestaciones.

44 Romanos, 96. 